\title{
A Rare Case of Hypodontia in Kawasaki Disease: Review of the Literature
} and Case Report

\section{Kolokitha OE ${ }^{1}$, Chatzistavrou $E^{2 *}$ and Almpani $K^{3}$}

${ }^{1}$ Assistant Professor, Department of Orthodontics, School of Dentistry, Aristotle University of Thessaloniki, Thessaloniki, Greece

${ }^{2}$ Orthodontist, Private Practice, Thessaloniki, Greece

${ }^{3}$ Orthodontist

\begin{abstract}
Kawasaki disease $(\mathrm{KD})$ is a rare idiopathic infantile multi-organ vasculitis of medium-sized arteries that predominantly affects children younger than the age of 5 years. Besides the persistent fever of 5 or more days and among the typical criteria for the diagnosis of KD, a dentist may encounter oral manifestations such as "strawberry tongue", red or dry fissured lip and oropharyngeal erythema. If left untreated, the disease may have fatal prognosis due to the involvement of vital organs.
\end{abstract}

Hypodontia belongs to the most common congenital anomalies in humans. Genetic studies suggest both genetic and environmental etiology toward this anomaly. It is frequently associated with other oral anomalies and altered craniofacial growth. Different health problems have been observed in patients with hypodontia.

In the literature, the finding of hypodontia in KD is very rare. This article aims to report a case of a Caucasian 8 year-old boy with hypodontia, who was treated in the age of 7 months for KD. A short review of the literature regarding the two conditions is presented.

Keywords: Kawasaki disease; Hypodontia; Tooth agenesis; Oligodontia; Congenital anomalies

\section{Introduction}

Changes in the number of teeth characterize the most common congenital anomalies in humans $[1,2]$. Tooth agenesis is the congenital lack of one or more permanent teeth. In the case of lack of up to 6 teeth, this anomaly is called "hypodontia", either mild or moderate. When the number of missing teeth is more than 6 , excluding the third molar, the condition is characterized as severe hypodontia. The terms "oligodontia" (i.e. a few teeth present) and "anodontia" (i.e. complete lack of teeth) are rather historical [3]. The prevalence of hypodontia is reported to vary between 2.6 and 11.3 per cent, depending on demographic and geographic profiles [4-17]. There is also a preference for women compared to men [18]. Clinicians often claim that dental agenesis is increased during recent decades $[19,20]$. There is no evidence, though, as to whether this is an evolutionary trend or an observation, as a result of more advanced screening and diagnosis of oral anomalies in general. In the permanent dentition (excluding third molars), mandibular second premolars are the most frequently missing teeth, followed by the maxillary lateral incisors and second premolars [20-22].

Hypodontia is frequently associated with other oral anomalies, such as cleft lip and/or palate [23,24], microdontia and/or malformation of other teeth [22,25-29], impaction, delayed formation and/or delayed eruption of other teeth [30-35], malposition of other teeth [36-38], maxillary canine/first premolar transposition $[39,40]$, taurodontism [31,35,38,41], enamel hypoplasia [26] and altered craniofacial growth $[42,43]$. Several studies associate hypodontia with smaller cranial base length [42-44] and angle [42], more retrognathic [45-48] and shorter in length maxilla [42-44,47,49], smaller mandibular plane $[44,45,50]$ and sagittal jaw relationship angles $[45,46]$, more prognathic mandible $[42,44,50]$, greater retroclination of maxillary $[42,45,46,48]$ and mandibular incisors $[42,43,45,46]$, straighter facial convexity $[30,45,47,48]$, larger interincisal angle $[30,42,45,48]$, shorter lower anterior facial height $[44,45]$ and a more counter-clockwise rotated occlusal plane [43]. Interestingly though, some other studies state little or no effect of hypodontia on craniofacial morphology [51-53].

Tooth agenesis may be classified as syndromic/non-syndromic and familial/sporadic. While the nature of syndromic or familial agenesis provides information on mechanisms of the disease, nonsyndromic and sporadic agenesis is of special interest due to the lack of apparent mechanism underlying its induction. In the majority of cases, hypodontia has genetic causes. The contribution of genetic factors to dental agenesis has not been clarified yet [54], although a significant progress has been made in the understanding of the mechanisms involved. Moreover, the pathogenesis of hypodontia cannot be explained by genetic factors alone, since monozygotic twins show discordant expression at a certain frequency with respect to hypodontia [55]. The disease is thought to have a connection with some environmental factors, such as infection (e.g. rubella) [56], the use of certain chemical substances and drugs during pregnancy, chemo- and radiotherapy [54-57]. Different kinds of trauma in the apical area of the dentoalveolar processes (fractures, extraction of temporary tooth) may also contribute to the pathogenesis of tooth agenesis [4]. However, the environmental aetiology of hypodontia is not yet fully understood.

On the other hand, according to the results of a retrospective study in a population of Japanese orthodontic patients, predisposing general health problems, especially allergy, seem to be involved [58]. General health problems observed more frequently in patients with hypodontia include allergy, enlarged adenoids, asthma, atopy, bronchitis, stuffy nose, exudative otitis media, Basadow's disease, atelectasis, acute lymphocytic leukaemia, epilepsy, haemangioma, hydrocephalus, infectious mononucleosis, neonatal jaundice, liver cancer, low birth weight, pyloristenosis, rubella, sialolithiasis, varicella and Kawasaki’s disease [58].

*Corresponding author: Evangelia K. Chatzistavrou, DDS, MSc, DrDent Orthodontist, Private practice, 5 Agias Theodoras Str., GR 54623 Thessaloniki, Greece, Tel: +30 2310 225235; Fax: +30 2310 225285; E-mail: liaortho@hotmail.com

Received September 17, 2013; Accepted October 14, 2013; Published October 16,2013

Citation: Kolokitha OE, Chatzistavrou E, Almpani K (2013) A Rare Case of Hypodontia in Kawasaki Disease: Review of the Literature and Case Report Dentistry 3: 164. doi:10.4172/2161-1122.1000164

Copyright: $\odot 2013$ Kolokitha et al. This is an open-access article distributed under the terms of the Creative Commons Attribution License, which permits unrestricted use, distribution, and reproduction in any medium, provided the original author and source are credited. 
Kawasaki disease $(\mathrm{KD})$ is an acute self-limited vasculitis of unknown etiology that affects predominantly infants and children younger than 5 years of age. It was first described as Mucocutaneous Lymph Node Syndrome (MLNS) by the Japanese pediatrician Dr. Tomisaku Kawasaki who in 1967, diagnosed 50 cases, in which a rash and fever in early childhood were accompanied by edema, conjunctival infection, redness and cracking of the lips, "strawberry tongue", convalescent desquamation, and occasionally lymphadenopathy $[59,60] . \mathrm{KD}$ is considered a kind of systemic vasculitis syndrome that primarily invades the medium-sized muscular arteries including coronary arteries [61]. Despite the fact that the disease is mostly prevalent in Japan and East Asian countries (with an annual incidence of about 112 cases per 100,000 children $<5$ years old), it has been reported all over the world and is now known to occur in both endemic and communitywide epidemic forms in the United States, Europe and Asia, in children of all races [62]. Epidemiologic data suggest that susceptibility to KD depends more upon racial factors than geographic reasons [63]. It affects boys more often than girls (1.5:1 male: female ratio) $[64,65]$ and, although it occurs year round, cases tend to cluster in the winter and spring [64].

Diagnosis of KD is based on the presence of fever persisting for 5 days or more, associated with other transient typical signs, that rarely is simultaneously present at the time of first observation, but can appear subsequently [66]. These symptoms are bilateral conjunctival congestion, redness of the lips and oral mucosa, polymorphous skin rashes, reddening of the palms and soles followed by membranous desquamation and acute non-purulent cervical lymphadenopathy [61]. The most serious complications are coronary artery aneurysms or ectasia which develop in $15-25 \%$ of untreated children with the disease and may lead to myocardial infarction, sudden death, or ischemic heart disease [62].

The average duration of Kawasaki disease is 6-8 weeks and is characterized by 3 phases. Most signs and symptoms appear during the initial acute febrile phase, which lasts 1-2 weeks. The subacute phase follows after, until approximately day 25 , where desquamation, arthritis and althralgia occur with elevated platelet counts. Finally, during the convalescent phase, the clinical signs and symptoms disappear. Management of KD is aimed at reducing inflammation in the myocardium and the coronary arterial walls during the acute phase of the disease, and preventing coronary thrombosis. It involves the administration of intravenous immunoglobulin (IVIG) and high-dose aspirin as soon as the diagnosis is made [62].

The purpose of this article is to report a case of a Caucasian boy with hypodontia who was treated in the age of 7 months for Kawasaki disease and has not had any related or other general health problems since. A short literature on both conditions is presented.

\section{Case Presentation}

An eight year-old Caucasian male was presented by his parents to the Orthodontic Department of the Dental School of the Aristotle University of Thessaloniki, in Greece. The patient's chief complaint was "the gaps between his teeth". According to his medical history, the boy was successfully treated in the age of seven months for Kawasaki disease and has not had any related or other general health problems since. No similar medical anamnestic data were reported in the family regarding Kawasaki disease and/or hypodontia. The facial extraoral examination revealed a straight profile type and a small asymmetry of the lower third of the face, because of a slight deviation of the chin to the left (Figures 1a and $b$ ). Intraoral examination and study models

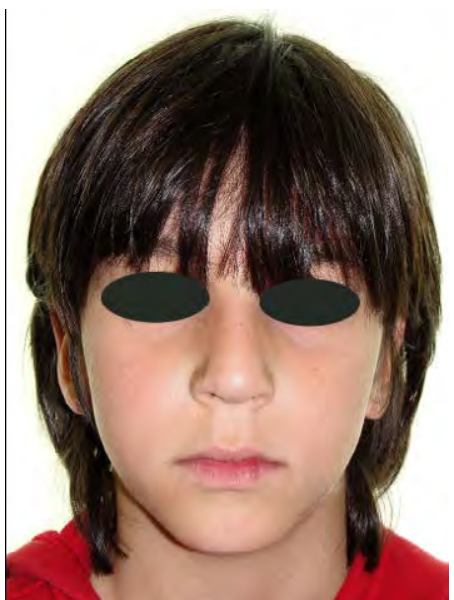

Figure 1a: Extraoral frontal view.

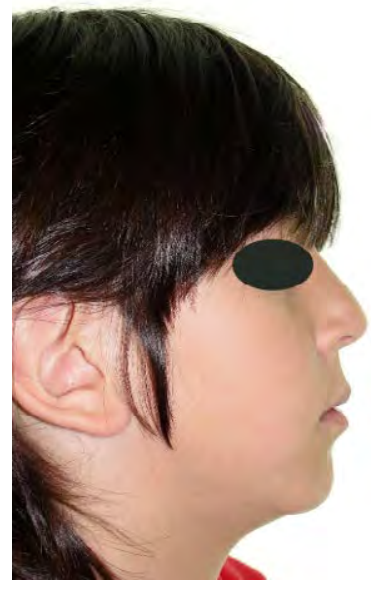

Figure 1b: Extraoral profile view.

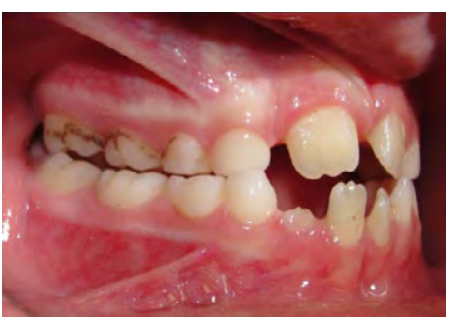

Figure 2a: Intraoral lateral right view.

indicated early mixed dentition, Class I molar relationship, an overjet of $1 \mathrm{~mm}$, an openbite of $-3 \mathrm{~mm}$, unilateral posterior crossbite on the right side and a functional shift of the mandible due to premature contacts of the primary canines on both sides (Figures 2a-c). Oral hygiene was of a moderate standard, with staining mainly on the posterior dental surfaces. The pretreatment panoramic radiograph (Figure 3 ) revealed six permanent teeth missing-all four second premolars, upper left first premolar and upper right lateral incisor-indicating a case of hypodontia. The cephalometric analysis of the pretreatment lateral cephalometric radiograph (Figure 4), showed normal growth pattern, straight profile of the hard tissues, small cranial base length, retrognathic maxilla and prognathic mandible, with a slightly bigger mandibular body and the 


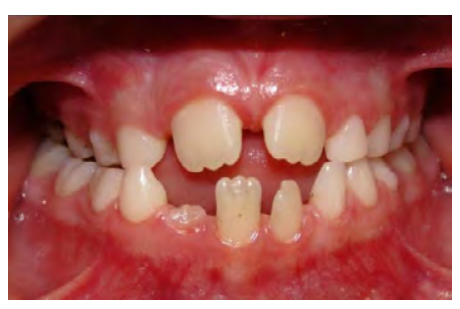

Figure 2b: Intraoral front view.

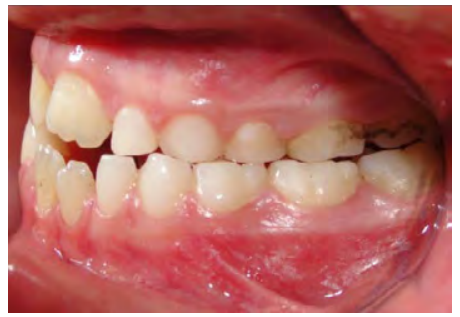

Figure 2c: Intraoral lateral left view.

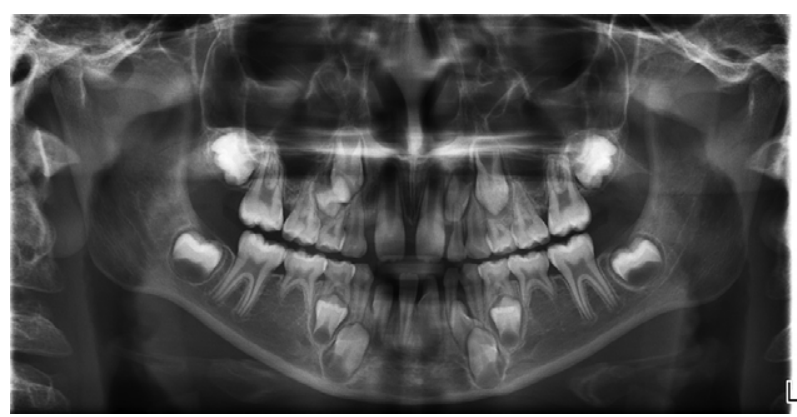

Figure 3: Pretreatment panoramic radiograph.

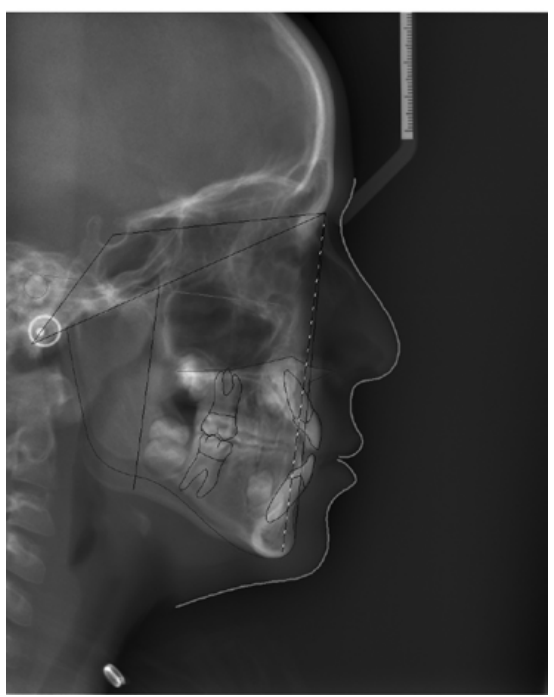

Figure 4: Pretreatment lateral cephalometric radiograph and tracing.

chin projecting in a more forward position. Lower incisors were not retroclined but were relatively forward positioned in relation to their osseous base, whereas upper incisors were normally inclined. No dental or osseous lesions were detected in the above radiographs. The aim of the patient's treatment was the correction of his malocclusion and the preparation of the mouth for future prosthetic work, due to the multiple missing teeth. This involves a multidisciplinary approach, comprising of the cooperation of an orthodontist and a prosthodontist. The orthodontic treatment plan consists of a Hyrax appliance combined with a Delaire face mask for the correction of the skeletal malocclusion, and fixed orthodontic appliances to arrange the teeth in the most proper position to receive the future prosthetic restoration. The finalized prosthetic rehabilitation will take place upon completion of growth of the young patient.

\section{Discussion}

KD is a disease that may affect the patient's general health in multiple ways and cause several serious systematic disturbances. It usually appears at an early age, coinciding with the age of tooth formation. In the literature, there is only one study reporting that $\mathrm{KD}$ belongs to a group of general health problems that has been found to co-exist with hypodontia. In total of 3683 Japanese orthodontic patients, 215 had hypodontia and only one of those had been sick with $\mathrm{KD}$ in childhood. The above study aimed to identify the etiological factors underlying hypodontia by investigating the general health problems of Japanese orthodontic patients with hypodontia. However, the association between the two conditions could not be clarified [66].

In the case presented, the two conditions co-exist. The patient has been diagnosed and treated at the age of 7 months as $\mathrm{KD}$. He presents hypodontia with six missing teeth. The findings of his cephalometric analysis are in agreement with several studies associated with hypodontia, characterized by smaller cranial base length [42-44], more retrognathic maxilla [45-48], more prognathic mandible [42,44,50], retroclined maxillary incisors $[42,45,46,48]$ and straighter facial convexity $[45,47,48]$.

Hypodontia creates esthetic problems, may cause masticatory and speech dysfunctions and is a matter of concern to most parents. A dentist is the first person to identify the problem of hypodontia and is the one who first determines the type of the inheritance pattern. This is the reason why it is of great importance to take a comprehensive medical history. The knowledge of a combined medical situation will enable the health professional in rendering the appropriate treatment to improve the esthetics. All medical conditions should be accurately understood before any treatment is planned. Patients and their parents should be well informed of all the options; in so, an ideal treatment plan can be formed for their benefit.

In the literature, only recently, $\mathrm{KD}$ has been related with lip swelling as a late symptom [67]. It should be wise for the dentists to be suspicious and alert with the oral manifestations of $\mathrm{KD}$ as they might be playing an important role in the early diagnosis of this rare disease. In children with medical history of the Kawasaki disease, and in need for dental treatment, a possible antibiotic prophylaxis would most probably be required before the intervention of the dental practitioner. In such a case, the doctor following the KD patient should prescribe the appropriate antibiotic medication.

The case presented is a rare report of hypodontia in a KD patient. It is important though, because of our limited present knowledge regarding the etiology of hypodontia, to report every health condition that has been found and might be related to it. Moreover, this is also a rare case of Kawasaki disease, due to the sparseness of the specific condition in Europe. 
Citation: Kolokitha OE, Chatzistavrou E, Almpani K (2013) A Rare Case of Hypodontia in Kawasaki Disease: Review of the Literature and Case Report. Dentistry 3: 164. doi:10.4172/2161-1122.1000164

\section{References}

1. Vastardis $\mathrm{H}(2000)$ The genetics of human tooth agenesis: new discoveries for understanding dental anomalies. Am J Orthod 117: 650-656.

2. Nunn JH, Carter NE, Gillgrass TJ, Hobson RS, Jepson NJ, et al. (2003) The interdisciplinary management of hypodontia: background and role of paediatric dentistry. Br Dent J 194: 245-251.

3. Arte S, Nieminen P, Apajalahti S, Haavikko K, Thesleff I, et al. (2001) Characteristics of incisor-premolar hypodontia in families. J Dent Res 80: 14451450.

4. Schalk van der Weide Y (1992) Oligodontia: a clinical, radiographic and genetic evaluation. Thesis, University of Utrecht.

5. Muller TP, Hill IN, Peterson AC, Blayney JR (1970) A survey of congenitally missing permanent teeth. J Am Dent Assoc 81: 101-107.

6. Graber LW (1978) Congenital absence of teeth: a review with emphasis on inheritance patterns. J Am Dent Assoc 96: 266-275.

7. Thompson GW, Popovich F (1974) Probability of congenitally missing teeth results in 1,191 children in the Burlington Growth Center in Toronto. Community Dent Oral Epid 2: 26-32.

8. Lynham A (1990) Panoramic radiographic survey of hypodontia in Australian Defence Force recruits. Aust Dent J 35: 19-22.

9. Salama FS, Abdel-Megid FY (1994) Hypodontia of primary and permanent teeth in a sample of Saudi children. Egypt Dent J 40: 625-632.

10. Johannsdottir B, Wisth PJ, Magnusson TE (1997) Prevalence of malocclusion in 6-year-old Icelandic children. Acta Odontol Scand 55: 398-402.

11. Rølling S, Poulsen S (2001) Oligodontia in Danish schoolchildren. Acta Odonto Scand 59: 111-112.

12. Nordgarden H, Jensen JL, Storhaug K (2002) Reported prevalence of congenitally missing teeth in two Norwegian countries. Community Dent Health 19: $258-261$.

13. Cho SY, Lee CK, Chan JC (2004) Congenitally missing maxillary permanent canines: report of 32 cases from an ethnic Chinese population. Inter J Paed Dent 14: 446-450.

14. Larmour CJ, Mossey PA, Thind BS, Forgie AH, Stirrups DR (2005) Hypodontia - a retrospective review of prevalence and etiology. Part I. Quint Inter 36: 263270

15. Flores-Mir C (2005) More women in Europe and Australia have dental agenesis than their counterparts in North America. Evid Based Dent 6: 22-23.

16. Lombardo C, Barbato E, Leonardi R (2007) Bilateral maxillary canines agenesis: a case report and a literature review. Eur J Paed Dent 8: 38-41.

17. Bondemark L, Tsiopa J (2007) Prevalence of ectopic eruption, impaction, retention and agenesis of the permanent second molar. Angle Orthod 77: 773778.

18. Symons AL, Stritzel F, Stamatiou J (1993) Anomalies associated with hypodontia of the permanent lateral incisors and second premolars. J Clin Pediatr Dent 17: 109-111.

19. Mattheeuws N, Dermaut L, Martens G (2004) Has hypodontia increased in Caucasians during the $20^{\text {th }}$ century? A meta-analysis. Eur J Orthod 26: 99-103.

20. Flores-Mir C (2006) Increased hypodontia through the twentieth century. Evid Based Dent 7: 15 .

21. Chosack A, Eidelman E, Cohen T (1975) Hypodontia: a polygenic trait. A family study among Israeli Jews. J Dent Res 54: 16-19.

22. Brook AH (1984) A unifying aetiological explanation for anomalies of human tooth number and size. Arch Oral Biology 29: 373-378.

23. Slayton RL, Williams L, Murray L, Murray JC, Wheeler JJ, et al. (2003) Genetic association studies of cleft lip and/or palate with hypodontia outside the cleft region. Cleft Palate Craniofac J 40: 274-279.

24. Kim NY, Baek SH (2006) Cleft sidedness and congenitally missing or malformed permanent maxillary lateral incisors in Korean patients with unilateral cleft lip and alveolus or unilateral cleft lip and palate. Am J Orthod 130: 752-758.

25. Garn SM, Lewis AB (1970) The gradient and the pattern of crown-size reduction in simple hypodontia. Angle Orthod 40: 51-58.
26. Baccetti T (1998) A controlled study of associated dental anomalies. Angle Orthod 68: 267-274.

27. Schalk van der Weide Y, Steen WH, Beemer FA, Bosman F (1994) Reductions in size and left-right asymmetry of teeth in human oligodontia. Arch Oral Bio 39: 935-939.

28. McKeown HF, Robinson DL, Elcock C, al-Sharood M, Brook AH (2002) Tooth dimensions in hypodontia patients, their unaffected relatives and a control group measured by a new image analysis system. Eur J Orthod 24: 131-141.

29. Albashaireh ZS, Khader YS (2006) The prevalence and pattern of hypodontia of the permanent teeth and crown size and shape deformity affecting upper lateral incisors in a sample of Jordanian dental patients. Community Dent Health 23: 239-243.

30. Brin I, Becker A, Shalhav M (1986) Position of the maxillary permanent canine in relation to anomalous or missing lateral incisors: a population study. Eur $\mathrm{J}$ Orthod 8: 12-16.

31. Schalk van der Weide Y, Steen WH, Bosman F (1993) Taurodontism and length of teeth in patients with oligodontia. J Oral Rehabil 20: 401-412.

32. Mossey PA, Campbell HM, Luffingham JK (1994) The palatal canine and the adjacent lateral incisor: a study of a west of Scotland population. $\mathrm{Br} \mathrm{J}$ Orthod 21: $169-174$

33. Peck S, Peck L, Kataja M (1996) Site-specificity of tooth agenesis in subjects with maxillary canine malpositions. Angle Orthod 66: 473-476.

34. Uslenghi S, Liversidge HM, Wong FS (2006) A radiographic study of tooth development in hypodontia. Arch Oral Biol 51: 129-133.

35. Ezoddini AF, Sheikhha MH, Ahmadi H (2007) Prevalence of dental development anomalies: a radiographic study. Community Dent Health 24: 140-144.

36. Zilberman Y, Cohen B, Becker A (1990) Familial trends in palatal canines, anomalous lateral incisors and related phenomena. Eur J Orthod 12: 135-139.

37. Svinhufvud E, Myllärniemi S, Norio R (1988) Dominant inheritance of tooth malpositions and their association to hypodontia. Clin Genet 34: 373-381.

38. Pirinen S, Arte S, Apajalahti S (1996) Palatal displacement of canine is genetic and related to congenital absence of teeth. J Dent Res 75: 1742-1746.

39. Peck L, Peck S, Attia Y (1993) Maxillary canine-first premolar transposition associated dental anomalies and genetic basis. Angle Orthod 63: 99-109.

40. Camilleri S (2005) Maxillary canine anomalies and tooth agenesis. Eur $J$ Orthod 27: 450-456

41. Calvano Küchler E, De Andrade Risso P, De Castro Costa M, Modesto A, Vieira AR (2008) Assessing the proposed association between tooth agenesis and taurodontism in 975 paediatric subjects. Int J Paediatr Dent 18: 231-234.

42. Endo T, Yoshino S, Ozoe R, Kojima K, Shimooka S (2004) Association of advanced hypodontia and craniofacial morphology in Japanese orthodontic patients. Odontology 92: 48-53.

43. Endo T, Ozoe R, Yoshino S, Shimooka S (2006) Hypodontia patterns and variations in craniofacial morphology in Japanese orthodontic patients. Angle Orthod 76: 996-1003.

44. Woodworth DA, Sinclair PM, Alexander RG (1985) Bilateral congenital absence of maxillary lateral incisors: a craniofacial and dental cast analysis. Am J Orthod 87: $280-293$

45. Øgaard B, Krogstad O (1995) Craniofacial structure and soft tissue profile in patients with severe hypodontia. Am J Orthod Dentofacial Orthop 108: 472-477.

46. Sarnäs KV, Rune B (1983) The facial profile in advanced hypodontia: a mixed longitudinal study of 141 children. Eur J Orthod 5: 133-143.

47. Wisth PJ, Thunold K, Böe OE (1974) The craniofacial morphology of individuals with hypodontia. Acta Odontol Scand 32: 281-290.

48. Ben-Bassat Y, Brin I (2003) Skeletodental patterns in patients with multiple congenitally missing teeth. Am J Orthod Dentofacial Orthop 124: 521-525.

49. Tavajohi-Kermani H, Kapur R, Sciote JJ (2002) Tooth agenesis and craniofacial morphology in an orthodontic population. Am J Orthod Dentofacial Orthop 122 39-47.

50. Nodal M, Kjaer I, Solow B (1994) Craniofacial morphology in patients with multiple congenitally missing permanent teeth. Eur J Orthod 16: 104-109. 
Citation: Kolokitha OE, Chatzistavrou E, Almpani K (2013) A Rare Case of Hypodontia in Kawasaki Disease: Review of the Literature and Case Report. Dentistry 3: 164. doi:10.4172/2161-1122.1000164

51. Roald KL, Wisth PJ, Bøe OE (1982) Changes in craniofacial morphology of individuals with hypodontia between the ages of 9 and 16. Acta Odontol Scand 40: 65-74.

52. Yüksel S, Uçem T (1997) The effect of tooth agenesis on dentofacial structures. Eur J Orthod 19: 71-78.

53. Laganà G, Lombardi CC, Franchi L, Cozza P (2011) Tooth agenesis: dentoskeletal characteristics in subjects with orthodontic treatment need. Eur $J$ Paediatr Dent 12: 17-20.

54. Pawlowska E, Janik-Papis K, Wisniewska-Jarosinska M, Szczepanska $\mathrm{J}$, Blasiak J (2009) Mutations in the human homeobox MSX1 gene in the congenital lack of permanent teeth. Tohoku J Exp Med 217: 307-312.

55. Markovic M (1982) Hypodontia in twins. Swed Dent J Suppl 15: 153-162.

56. Guliksson JS (1975) Tooth morphology in rubella syndrome children. ASDC J Dent Child 42: 479-482.

57. Maguire A, Craft AW, Evans RG, Amineddine H, Kernahan J, et al. (1987) The long term effects of treatment on the dental condition of children surviving malignant disease. Cancer 60: 2570-2575.

58. Yamaguchi T, Tomoyasu Y, Nakadate T, Oguchi K, Maki K (2008) Allergy as a predisposing factor for hypodontia. Eur J Orthod 30: 641-644.

59. Kawasaki T (1967) Acute febrile mucocutaneous syndrome with lymphoid involvement with specific desquamation of fingers and toes in children. Clinical observation of 50 patients. Jpn J Allergy 16: 178-222.
60. Kawasaki T, Kosaki F, Okawa S, Shigematsu I, Yanagawa H (1974) A new infantile acute febrile mucocutaneous lymph node syndrome (MLNS) prevailing in Japan. Pediatrics 54: 271-276.

61. Ayusawa M, Sonobe T, Uemura S, Ogawa S, Nakamura Y, et al. (2005) Revision of diagnosis guidelines for Kawasaki disease (the $5^{\text {th }}$ revised edition) Pediatr Int 47: 232-234.

62. Newburger JW, Takahashi M, Gerber MA, Gewitz MH, Tani LY, et al. (2004) Diagnosis, Treatment, and Long-Term Management of Kawasaki Disease: A Statement for Health Professionals From the Committee on Rheumatic Fever, Endocarditis and Kawasaki Disease, Council on Cardiovascular Disease in the Young, American Heart Association. Circulation 110: 2747-2771.

63. Takahashi K, Oharaseki T, Yokouchi Y (2011) Pathogenesis of Kawasaki disease. Clin Exp Immunol 164: 20-22.

64. Cox JR, Sallis RE (2009) Recognition of Kawasaki disease. Perm J 13: 57-61.

65. Pemberton MN, Doughty IM, Middlehurst RJ, Thornhill MH (1999) Recurrent Kawasaki disease. Br Dent J 186: 270-271.

66. Vierucci F, Tuoni C, Moscuzza F, Saggese G, Consolini R (2013). Erythema multiforme as first sign of incomplete Kawasaki disease. Ital J Pediatr 39: 11

67. Faden A (2013) Recurrent lip swelling as a late presentation of Kawasaki disease: Case report and review of the literature. Saudi Dent J 25: 43-47. 